\title{
Сорбция ионов меди угольным сорбентом МИУ-С
}

\author{
Линников О.Д., Родина И.В., Сунцов А.Ю. \\ ФГБУН Институт химии твёрдого тела УрО РАН, Екатеринбург
}

Поступила в редакцию 4.03.2017 г.

\begin{abstract}
Изучены сорбционные свойства по отношению к ионам меди угольного сорбента марки МИУ-C4. Исследования проводились на модельном растворе сульфата меди(II), содержащем дополнительно 400 мг/дм ${ }^{3}$ сульфата натрия.

Показано, что угольный сорбент марки МИУ-С4 способен очищать загрязнённые растворы от ионов двухвалентной меди путём сорбции их на своей поверхности по механизму простой физической адсорбции, описываемой уравнением Ленгмюра. Определены параметры этого уравнения для разных значений $\mathrm{pH}$ модельного раствора. С повышением $\mathrm{pH}$ очищаемого раствора от 4 до 6.7 адсорбция ионов меди на поверхности МИУ-С4 возрастает (диапазоны $\mathrm{pH}<4$ и $\mathrm{pH}>6.7$ не были исследованы), что обусловлено ростом ёмкости монослоя МИУ-С4. При этом наблюдается также возрастание константы адсорбционного равновесия.
\end{abstract}

Ключевые слова: сорбция, активированный уголь, угольный сорбент очистка воды, ионы меди(II), адсорбция, уравнение Ленгмюра.

\section{The sorption of ions $\mathrm{Cu}(\mathrm{II})$ by carbon sorbent MIU-C4}

\author{
Linnikov O.D., Rodina I.V., Syntsov A.Yu. \\ Institute of Solid State Chemistry, Ekaterinburg
}

The sorption properties of carbon sorbent MIU-C4 in relation of copper ions were studied. The study was carried out using a model solution of copper(II) sulfate containing additionally $400 \mathrm{mg} / \mathrm{l}$ of sodium sulfate. The determined specific surface area of the investigated sample of carbon sorbent MIU-C4 was near $22.27 \mathrm{~m}^{2} / \mathrm{g}$, specific surface area of pores was $0.25 \mathrm{~m}^{2} / \mathrm{g}$. At introduction of MIU-C4 into the model solution slight increasing in $\mathrm{pH}$ of the solution was observed. It was shown that carbon sorbent MIU-C4 may remove copper ions from polluted waters due to their physical adsorption on surface of the sorbent, and the sorption process is well described by the Langmuir equation. The parameters of this equation were determined for different $\mathrm{pH}$ of the model solution. It was established that adsorption of ions $\mathrm{Cu}^{2+}$ onto surface of MIU-C4 increases when $\mathrm{pH}$ of solution increases from 4 to 6.7 (the ranges of $\mathrm{pH}<4$ and $\mathrm{pH}>6.7$ were not investigated). This effect is caused by increasing of the adsorption capacity of MIU-C4. So for $\mathrm{pH}=4$ the adsorption capacity of MIU-C4 is near $0.265 \mathrm{mg} / \mathrm{g}$ or $0.012 \mathrm{mg} / \mathrm{m}^{2}$, for $\mathrm{pH}=5-1.981 \mathrm{mg} / \mathrm{g}$ or $0.044 \mathrm{mg} / \mathrm{m}^{2}$, for $\mathrm{pH}=6-$ $2.300 \mathrm{mg} / \mathrm{g}$ or $0.103 \mathrm{mg} / \mathrm{m}^{2}$, and for $\mathrm{pH}=6.7-3.307 \mathrm{mg} / \mathrm{g}$ or $0.149 \mathrm{mg} / \mathrm{m}^{2}$. The growth of the sorption equilibrium constant is also observed.

The comparison of sorption properties of MIU-C4 with analogous data for other carbon and mineral sorbents was also carried out. It is found that the adsorption capacity of MIU-C4 for ions $\mathrm{Cu}^{2+}$ in dimension of $\mathrm{mg} / \mathrm{g}$ is near of analogous ones for other sorbents.

Keywords: sorption, cleaning of water, ions $\mathrm{Cu}(\mathrm{II})$, adsorption, carbon sorbent, equation of Langmuir.

\section{Введение}

В настоящее время одной из самых актуальных задач для промышленности является очистка сточных вод от меди, что обусловлено очень низкой ПДК этих ио- 
нов в водах, сбрасываемых на «природу», в реки и озёра, так как последние в подавляющем своём большинстве относятся к водоёмам рыбохозяйственного значения. Так, ПДК ионов меди в водах таких водоёмов составляет всего 0.001 мг/дм³. По мнению многих специалистов столь жёсткое требование является необоснованным. И этот вопрос неоднократно поднимался в литературе [1]. Между тем, существующие традиционные методы очистки сточных вод предприятий с использованием известкового молока не позволяют достичь этого значения. Так, практика показывает, что остаточная концентрация ионов меди в сточных водах после их очистки путём известкования при $\mathrm{pH}=8-9$ обычно находится на уровне 0.1-0.2 мг/дм ${ }^{3}$ [1]. Выходом из создавшегося положения может быть применение сорбционной финишной доочистки сточных вод и, в частности, использование на этой стадии активированных углей и других угольных (углеродных) сорбентов.

Эти сорбенты уже давно используются для очистки газов, природных и сточных вод от загрязняющих примесей $[2,3]$. Наиболее часто их применяют для очистки воды от нефти и нежелательных органических соединений [2-7], а также от катионов тяжёлых металлов [8-12]. Например, сорбция ионов меди на разных марках углеродных (угольных) сорбентов изучалась в работах [8-10]. Однако для некоторых таких материалов, несмотря на их широкое использование, до сих пор не определён механизм сорбционного процесса и его параметры, что затрудняет их целенаправленное использование в технологиях очистки загрязнённых вод.

Целью данной работы является исследование сорбционных свойств угольного сорбента МИУ-С, выпускаемого ООО «МИУ-Сорб» (Москва), по отношению к ионам двухвалентной меди. Данный сорбент отличается от активированных углей и других углеродных сорбентов тем, что он производится из природных длиннопламенных углей (каменный уголь марки Д). Материал МИУ-С представляет собой твёрдый неорганический полимер, состоящий из нескольких угольных слоёв, которые связаны между собой силами Ван-дер-Ваальса [13-15]. Эти слои содержат в своём составе ароматические структуры и алифатические цепи углеводородов с атомами водорода, кислорода, азота и серы. В настоящее время МИУ-С нашёл широкое применение в промышленности для очистки вод от ионов железа, аммония, тяжёлых металлов, бактериального загрязнения, сероводорода, нефтепродуктов, фенолов, красителей и других загрязнителей [13-15]. Однако в литературе отсутствуют данные о его способности удалять из загрязнённых растворов ионы двухвалентной меди. Неизвестен механизм сорбции ионов меди МИУ-С и параметры сорбционного процесса. Данная работа является попыткой заполнить этот пробел. Представляет интерес также сравнение сорбционных свойств МИУ-С по отношению к ионам меди с другими угольными (углеродными) сорбентами.

\section{Эксперимент}

Угольный сорбент марки МИУ-С выпускается в нескольких модификациях, отличающихся крупностью частиц (МИУ-С1, МИУ-С2, МИУ-С3 и МИУ-С4). Модификация МИУ-С4 имеет размер частиц 0.06-0.6 мм. Она была выбрана нами для изучения сорбционных свойств. Этот выбор был обусловлен удобством проведения лабораторных исследований.

Эксперименты проводили на модельном водном растворе, имитирующем природные и сточные воды, который готовили путём растворения в дистиллированной воде сульфатов натрия и меди $\left(\mathrm{Na}_{2} \mathrm{SO}_{4}\right.$ и $\left.\mathrm{CuSO}_{4}\right)$. Концентрация сульфата натрия в модельном растворе была равна 400 мг/дм ${ }^{3}$, а ионов меди менялась в разных экспериментах, но не превышала 15 мг/дм³ . Все опыты проводили при комнатной тем- 
пературе $\left(25 \pm 2^{\circ} \mathrm{C}\right)$ и непрерывном перемешивании магнитной мешалкой модельного раствора, в который добавляли сорбент. Затем через 80 минут выдержки сорбент отделяли от раствора фильтрованием через бумажный фильтр «синяя лента». Процесс фильтрации занимал 20-30 мин. Таким образом, общее время контакта раствора с сорбентом составляло 100-110 мин. Как показали предварительные опыты, этого времени было достаточно для достижения сорбционного равновесия в растворе. При этом было обнаружено, что при фильтрации растворов с низкой концентрацией меди происходит её частичная сорбция на используемом бумажном фильтре, и концентрация ионов меди в отфильтрованном растворе снижается, что искажает результаты анализа. Чтобы избежать этого (или, по крайней мере, снизить ошибку определения меди) при фильтрации отобранной пробы через бумажный фильтр “синяя лента" первую порцию раствора, объёмом около $100 \mathrm{~cm}^{3}$, отбрасывали и на анализ брали оставшуюся, отфильтрованную через этот же фильтр, часть отобранной пробы раствора. Концентрацию меди(II) в растворе определяли фотоколориметрическим методом с диэтилдитиокарбаматом натрия на фотоколориметре КФК-2 [16]. Анализ раствора на другие компоненты проводили кислотно-основным и комплексонометрическим методами химического анализа $[17,18]$. Относительная погрешность определений составила $10 \%$.

Основные эксперименты были выполнены при разных значениях $\mathrm{pH}$ раствора, который контролировали с помощью рН-метра АНИОН 4100 (погрешность определения \pm 0.05 ед. $\mathrm{pH}$ ). Коррекция кислотности раствора до требуемого значения в этих опытах (и последующее его поддержание на заданном уровне в течение эксперимента) осуществлялась с помощью $0.1 \mathrm{~N}$ растворов серной кислоты и $\mathrm{NaOH}$, и проводилась только после ввода сорбента в модельный раствор. Отметим, что в этих и других подобных опытах электроды рН-метра были постоянно погружены в модельный раствор с сорбентом в течение всего эксперимента.

Удельная поверхность МИУ-С4 была определена методом БЭТ по адсорбции азота на установке Gemini VII 2390 V1.03 (USA).

\section{Обсуждение результатов}

Измерение удельной поверхности порошка МИУ-С4 показало, что она равна $22.27 \mathrm{~m}^{2} /$ г. При этом оказалось, что удельная поверхность пор составляет всего $0.25 \mathrm{~m}^{2} / \Gamma$. Полученный результат удивителен и объясняется, возможно, малым размером частиц сорбента и его низкой пористостью. Как известно, удельная поверхность активированных углей составляет обычно $100-1000 \mathrm{~m}^{2} / \Gamma$, что обусловлено их пористой структурой, так как именно поверхность пор вносит основной вклад в их общую удельную поверхность. Возможно, при измельчении угля, из которого делается сорбент МИУ-С4, эта пористая структура разрушается, вследствие того, что раскол частиц при дроблении будет происходить, по-видимому, в основном по каналам пор. И это может привести к тому, что частицы малых размеров почти не будут содержать пор.

При введении сорбента в раствор сульфата натрия наблюдалось небольшое повышение его рН (рис. 1), обусловленное, видимо, присутствием в МИУ-С4 малых количеств карбонатов кальция и магния, так как анализ раствора после выдержки в нём сорбента показал наличие в растворе бикарбонатных ионов $\left(30.5\right.$ мг/дм $\left.{ }^{3}\right)$, ионов кальция $\left(4 \mathrm{мг} /\right.$ дм $\left.^{3}\right)$ и магния $\left(2.4\right.$ мг/дм $\left.{ }^{3}\right)$. Из рис. 1 также видно, что значение $\mathrm{pH}$ раствора стабилизируется примерно через 80 минут с начала перемешивания его мешалкой. Исходя из этого, продолжительность последующих сорбционных экспериментов была выбрана равной 80 мин. Как уже упоминалось выше, предварительные 
опыты показали, что этого времени было достаточно для установления сорбционного равновесия в растворе. Экспериментальные данные также свидетельствуют о том, что увеличение концентрации МИУ-С4 не приводит к дальнейшему возрастанию $\mathrm{pH}$ раствора (рис. 2), но снижает концентрации в нём ионов меди (рис. 3). При этом рН раствора почти не меняется и лежит в диапазоне 5.57-5.88 ед. $\mathrm{pH}$ (см. рис. 3, где рядом с каждой экспериментальной точкой показано соответствующее ей значение $\mathrm{pH}$ раствора).

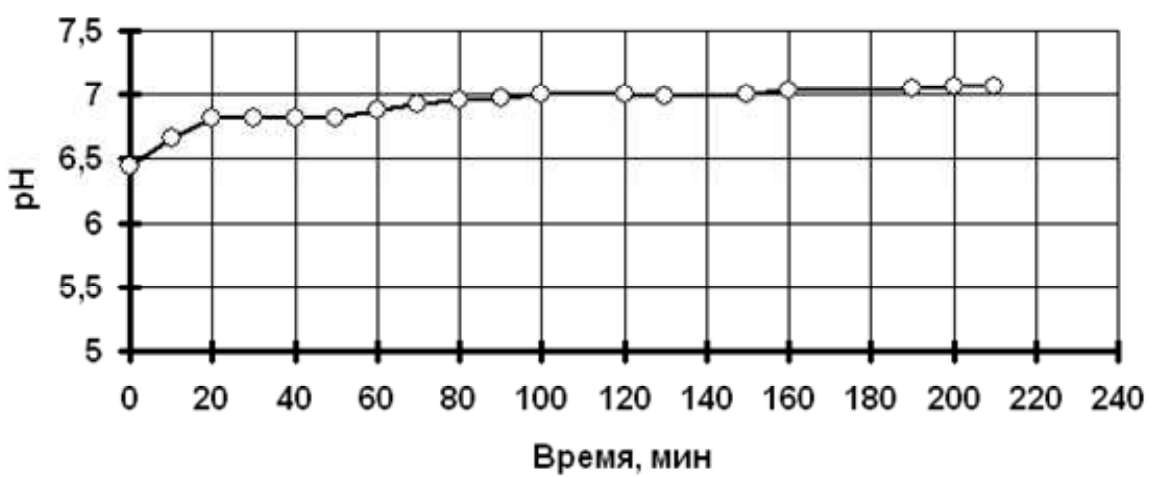

Рис. 1. Кинетика изменения $\mathrm{pH}$ раствора сульфата натрия (400 мг/дм³ при выдержке в нём сорбента МИУ-С4 при постоянном перемешивании суспензии магнитной мешалкой (концентрация сорбента в растворе $\mathrm{C}_{S}=2$ г/дм ${ }^{3}$ ).

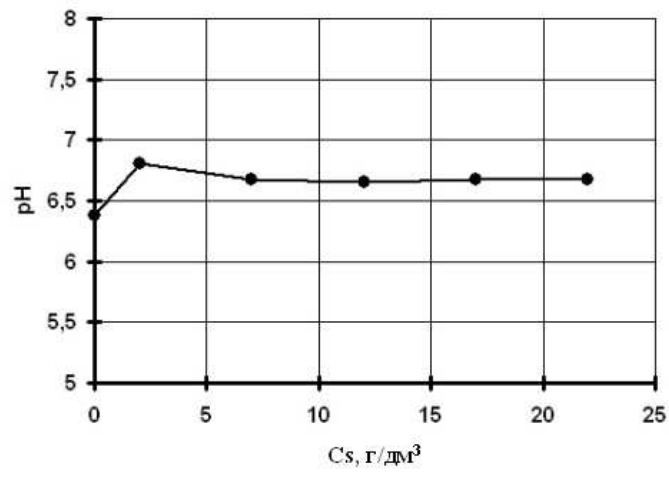

Рис. 2. Влияние концентрации сорбента МИУ-С4 на $\mathrm{pH}$ раствора сульфата натрия (400 мг/дм ${ }^{3}$, время выдержки сорбента в растворе 30 мин)

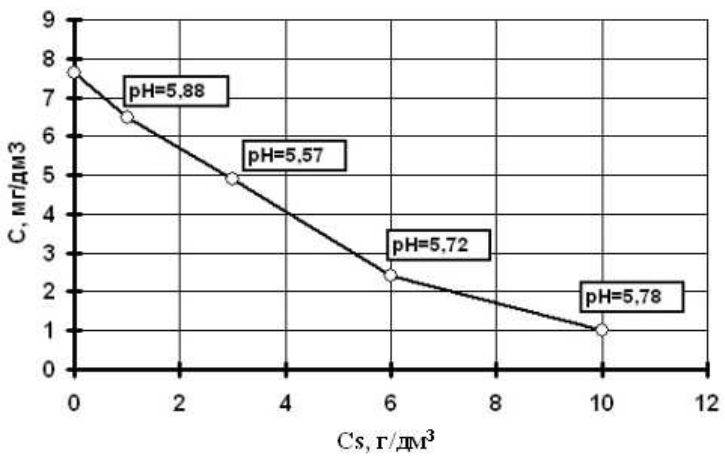

Рис. 3. Влияние концентрации МИУ-С4 на остаточное содержание (C) меди в модельном растворе (начальная концентрация ионов меди в растворе 7.632 мг/дм³ $)$

Обработка экспериментальных результатов, представленных на рис. 3, показала, что они хорошо описываются уравнением Ленгмюра для мономолекулярной адсорбции (рис. 4, прямая 1):

$$
A=A_{\infty} \frac{K \cdot C}{1+K \cdot C},
$$

где $A$ - величина адсорбции, мг/Г или мг/м² $A_{\infty}$ - ёмкость адсорбционного монослоя

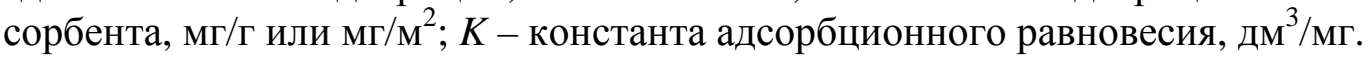

Аналогичные зависимости были получены при проведении сорбции при фиксированных значениях рН раствора (рис. 4, прямые 2 и 3). Как видно, во всех опытах экспериментальные точки хорошо аппроксимировались прямыми, подтверждающими справедливость уравнения Ленгмюра, что свидетельствует о протекании в данном случае простой мономолекулярной физической адсорбции ионов меди на поверхности сорбента МИУ-С4. 
Полученные данные позволили рассчитать параметры уравнения Ленгмюра (табл. 1). Отметим, что при $\mathrm{pH}<4$ адсорбция ионов меди сорбентом МИУ-С4 нами не изучалась, а при $\mathrm{pH}>6.7$ получить достоверные результаты не удалось из-за большой экспериментальной ошибки определения концентрации ионов меди в растворе.

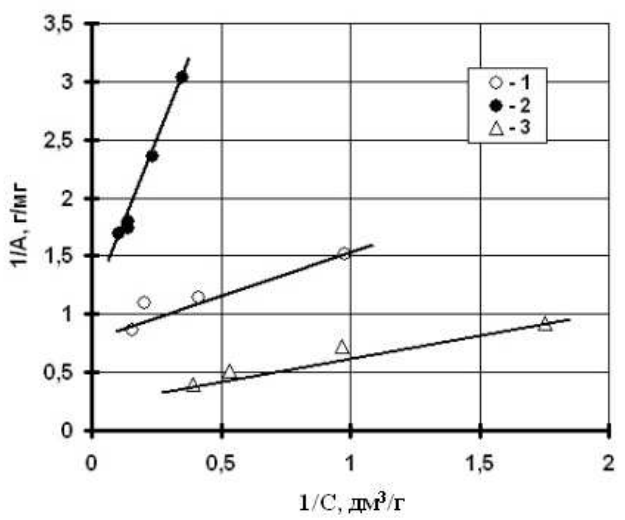

Рис. 4. Экспериментальные данные по сорбции ионов меди из модельного раствора сорбентом МИУ-С4 в координатах линейной формы уравнения (1): 1 - без коррекции $\mathrm{pH}$ раствора (данные рис. $3, \mathrm{pH}=5.57-5.88$, в среднем $\mathrm{pH}=5.74$ ); 2 - при $\mathrm{pH}=5$ (начальная концентрация ионов меди в растворе 12.72 мг/дм ${ }^{3}$ ); 3 - при $\mathrm{pH}=6.7$

(начальная концентрация ионов меди в растворе 3.816 мг/дм ${ }^{3}$ ).

Из данных табл. 1 видно, что ёмкость адсорбционного монослоя сорбента МИУ-С4 с повышением $\mathrm{pH}$ раствора монотонно возрастает. Одновременно с этим наблюдается рост константы адсорбционного равновесия. Значения параметров уравнения (1), найденные в экспериментах без коррекции $\mathrm{pH}$ раствора $(\mathrm{pH}=5.57$ 5.88), несколько “выбиваются" из общей зависимости (особенно это касается константы адсорбционного равновесия), что объясняется, по-видимому, колебаниями рН раствора в этих опытах.

Таблица 1. Зависимость параметров уравнения (1) от $\mathrm{pH}$ раствора, в котором протекает процесс сорбции ионов меди $\left(\mathrm{R}_{\mathrm{c}}-\right.$ коэффициент корреляции)

\begin{tabular}{|c|c|c|c|c|}
\hline $\mathrm{pH}$ & $A_{\infty}, \mathrm{MГ} / \Gamma$ & $A_{\infty}, \mathrm{M \Gamma} / \mathrm{M}^{2}$ & $K$, дм$^{3} / \mathrm{M \Gamma}$ & $\mathrm{R}_{\mathrm{c}}$ \\
\hline 4 & 0.2652 & 0.0119 & 0.1639 & 0.885 \\
\hline 5 & 1.9809 & 0.0440 & 0.1802 & 0.992 \\
\hline $5.74^{*}$ & 1.1621 & 0.0522 & 1.2765 & 0.948 \\
\hline 6 & 2.3004 & 0.1033 & 0.4689 & 0.992 \\
\hline 6.7 & 3.3069 & 0.1485 & 0.8188 & 0.979 \\
\hline
\end{tabular}

*Без коррекции рН раствора ( $\mathrm{pH}=5.57-5.88$, в среднем $\mathrm{pH}=5.74)$.

Представляет интерес сравнить найденные значения параметров уравнения Ленгмюра для сорбента МИУ-С4 с аналогичными величинами, опубликованными в литературе для других угольных (углеродных) сорбентов.

Так, в работе [8] была изучена сорбция ионов меди углеродными сорбентами марки АД-05-2 (удельная поверхность - не менее $640 \mathrm{~m}^{2} /$ г) и Сибунит (удельная поверхность - около $\left.450 \mathrm{~m}^{2} / \Gamma\right)$. Показано, что сорбция может быть описана уравнением Ленгмюра со следующими параметрами (для 20 ${ }^{\circ}$ ): АД-05-2 - $A_{\infty}=8100 \cdot 10^{-5}$

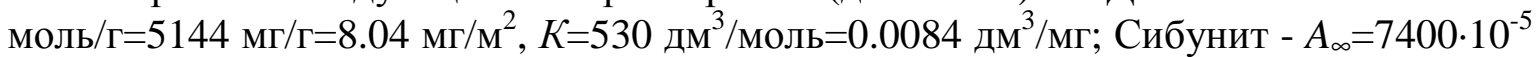

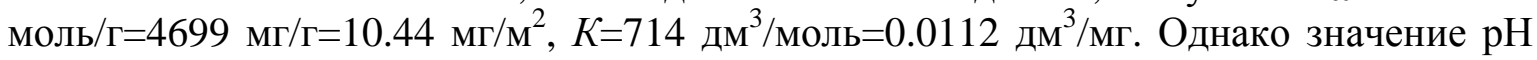
раствора, для которого определены эти параметры, не указано. 
Как видно, ёмкость адсорбционного монослоя сорбентов АД-05-2 и Сибунит по отношению к ионам меди в размерности мг/г на несколько порядков превышает

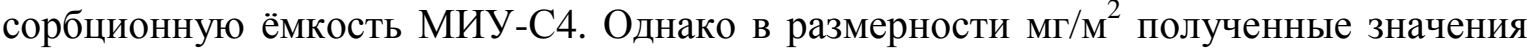
имеют уже разумную величину, но всё равно они примерно на два порядка выше ёмкости монослоя сорбента МИУ-С4. При этом в отношении констант адсорбционного равновесия наблюдается обратная зависимость - у углеродных сорбентов АД-05-2 и Сибунит они примерно на один - два порядка меньше, чем у МИУ-С4.

В работе [9] в динамическом режиме на углеродного сорбенте ИПИ-Т (удельная поверхность $\left.480 \mathrm{~m}^{2} / \Gamma\right)$ очистке от ионов меди и никеля подвергались реальные сточные воды гальванического производства после их предварительной электрокоагуляционной обработки. Найденная динамическая обменная ёмкость ИПИ-Т по ионам меди составила 3.5 мг/г (или $0.007 \mathrm{мг} / \mathrm{m}^{2}$ ). Полная обменная ёмкость сорбента

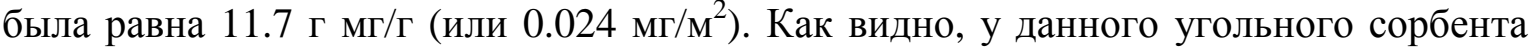
сорбционная ёмкость по ионам меди значительно ниже сорбционной ёмкости угольных сорбентов марки Сибунит и АД-05-2, которые имеют почти такую же удельную поверхность. Она также ниже ёмкости монослоя сорбента МИУ-С, изученного в данной работе.

Сорбционные свойства по отношению к ионам тяжёлых металлов активированного угля марки АГ-ОВ-1 и его модифицированной капролактамом формы АГOB-1кл были изучены в работе [10]. На модельном растворе, имитирующем стоки гальванического производства, изучалась статика, кинетика и динамика сорбции. Найденная равновесная адсорбционная ёмкость угля АГ-ОВ-1 составила $0.0251 \mathrm{мг} / г$, а для АГ-ОВ-1кл - 0.0376 мг/г. Значения $\mathrm{pH}$ раствора, при котором изучалась сорбция, не указан. Из сравнения с вышеприведёнными данными видно, что сорбционная ёмкость по ионам меди активированного угля марки АГ-ОВ-1 и его модифицированной формы АГ-ОВ-1кл в размерности мг/г ниже, чем у МИУ-С4 и близка к значениям найденным для углеродного сорбента ИПИ-Т. По данным, приведённым в работах [17 и 18], ёмкость монослоя различных минеральных сорбентов по отношению к ионам меди лежит в диапазоне от 1.01 до 55.56 мг/г.

\section{Заключение}

Таким образом, выполненные исследования показали, что угольный сорбент марки МИУ-С4 способен очищать загрязнённые растворы от ионов двухвалентной меди путём сорбции их на своей поверхности по механизму простой физической адсорбции, описываемой уравнением Ленгмюра. С повышением $\mathrm{pH}$ очищаемого раствора от 4 до 6.7 адсорбция ионов меди на поверхности МИУ-С4 возрастает (диапазоны $\mathrm{pH}<4$ и $\mathrm{pH}>6.7$ не были исследованы), что обусловлено ростом ёмкости монослоя МИУ-С4. При этом наблюдается также возрастание константы адсорбционного равновесия.

Адсорбционная ёмкость монослоя угольного сорбента МИУ-С4 по отношению к ионам меди близка по своему значению к аналогичным величинам для других минеральных сорбентов. Данный сорбент может быть рекомендован для очистки природных и сточных вод от ионов меди.

\section{Список литературы}

1. Виноградов С.С., Кудрявцев В.Н // Водоснабжение и канализащчия. 2010. № 5-6. С. 113-118.
2. Мухин В.М., Курилкин А.А., Воропаева Н.Л., Лексюкова К.В. и др. // Сорбиионные и 
хроматографические проиессы. 2016. Т. 16. № 3. С. 346-353.

3. Зорина Е.И. // Сборник докладов III межотраслевой конференции «Вода в промышленности-2012». М. 2012. С. 122-124.

4. Трифонова О.А. // Экология и промышленность России. 2000. С. 10-12.

5. Идрисова С.Ф., Гриневич В.И. // Химия и химическая технология. 2009. Т. 52. вып. 4. C. 41-44.

6. Мухин В.М., Курилкин А.А., Клушин В.Н. // Сорбиионные и хроматографические проиессы. 2013. Т. 13. Вып. 3. С. 188-191.

7. Шаймухаметова Г.Ф. Автореф. дис.... канд. хим. наук. Уфа, 2016. 24 с.

8. Сырых Ю.С. Автореф. дис.... канд. техн. наук. Иркутск. 2010. 29 с.

9. Филатова Е.Г., Анциферов Е.А., Помазкина О.И., Свитова А.О. // Сборник научных статей IX Международной научнотехнической конференции Наука, образование, производство в решении экологических проблем (экология-2012). Уфа. 2012. Т. 2. С. 259-263.

10. Юстратов В.П., Соловьёва Ю.В. // Вестник Кузбасского государственного

\section{References}

1. Vinogradov S.S., Kudryavtsev V.N., Water supply and sewerage, 2010, No 5-6, pp. 113118 (in Russian).

2. Mukhin V.M., Kurilkin A.A., Voropaeva N.L., Leksyukova K.V., Uchanov P.V., Sorbtsionnye i khromatograficheskie protsessy, 2016, Vol. 16, No 2, pp. 346-353 (in Russian).

3. Zorin E.I. Proceeding of III interindustry conference "Water in industry-2012", M., 2012, pp. 122-124 (in Russian).

4. Trifonova O.A. Ecology and industry of Russia, December, 2000, pp. 10-12 (in Russian).

5. Indrisova S.F., Grinevich V.I. Chemistry and chemical technology, 2009, Vol. 52, No 4, pp. 41-44 (in Russian).

6. Mukhin V.M., Kurilkin A.A., Klushin V.N. Sorbtsionnye i khromatograficheskie protsessy, 2013, Vol. 13, No 3, pp. 188-191 (in Russian).

7. Shaymukhametova G.F. Thesis for a $\mathrm{PhD}$ degree, Ufa, 2016, 24 p (in Russian).

8. Syryh Yu.S. Thesis for a PhD degree, Irkutsk, 2010, 29 p (in Russian). технического университета. 2006. № 1. С. 114-115.

11. Грищенко Э.С. Автореф. дис.... канд. техн. наук. Иркутск. 2005. 32 с.

12. Домрачёва В.А., Шийрав Г // Цветные металлы. 2013. № 1. С. 43-48.

13. Тарнопольская М.Г., Соловьёва Е.А. // Вода: Химия и экология. 2011. № 3. С. 52-57.

14. Тарнопольская М.Г. // Водоснабжение и санитарная техника. 2006. № 7. С. 35-39.

15. Тарнопольская М.Г., Hagger I. // Водоочистка, водоподготовка, водоснабжение. 2012. № 9. С. 56-63.

16. Новиков Ю.В., Ласточкин К.О., Болдина 3.Н. Методы исследования качества воды водоёмов. Изд. 2-е, дополненное и переработанное. М. Медицина. 1990. 400 с.

17. Лурье Ю.Ю. Справочник по аналитической химии. М. Химия. 1989. 448 с.

18. Унифицированные методы анализа вод. Под ред. д-ра хим. наук Ю.Ю. Лурье. М. Химия. $1973.376 \mathrm{c.}$

19. Aydin H., Yerlikaya C., Uzan S. // Desalination and Water Treatment. 2012. Vol. 44. pp. 296-305.

20. Coruh S., Geyikci F. // Desalination and Water Treatment. 2012. Vol. 45. pp. 351-360.

9. Filatova E.G., Antsiferov E.A., Pomazina O.I., Svitova A.O. Proceeding of IX International scientific and technical conference Science, edication, industry in solution of ecological problems (ecology-2012), Ufa, 2012, Vol. 2, pp. 259-263 (in Russian).

10. Yustratov V.P., Solov'yova Yu.V. Bulletin of Kuzbass state technical university, 2006, No 1, pp. 114-115 (in Russian).

11. Grishchenko E.S. Thesis for a PhD degree, Irkutsk, 2005, 32 p (in Russian).

12. Domracheva V.A., Shiirav G. Non-ferrous metals, 2013, No 1, pp. 43-48 (in Russian).

13. Tarnopol'skaya M.G., Solov'yova Water: Chemistry and ecology, 2011, No 3, pp. 52-57 (in Russian).

14. Tarnopol'skaya M.G. Water supply and sanitary engineering, 2006, No 7, pp. 35-39 (in Russian).

15. Tarnopol'skaya M.G., Hagger I. Water treatment, water preparation, water supply, 2012, No 9, pp. 56-63 (in Russian).

16. Novikov U.V., Lastochkin K.O., Boldina Z.N. Metody issledovania kachestva vody vo- 
doemov. M., Meditsina, 1990, 400 p (in Russian).

17. J.J. Lure, Directory of analytical chemistry, Chemistry, Moscow, 1989, 376 p. (in Russian).

18. The Unified Methods of the Analysis of Sewage, second ed., under the edit. of J.J. Lure, Chemistry, M., 1973 (in Russian).

Линников Олег Дмитриевич - Д.х.н., зав. лаб. Института химии твёрдого тела УрО РАН, Екатеринбург

Родина Ирина Васильевна - инженер 1-й категории Института химии твёрдого тела УрО РАН, Екатеринбург

Сунцов Алексей Юрьевич - к.х.н., старший научный сотрудник Института химии твёрдого тела УрО РАН, Екатеринбург
19. Aydin H., Yerlikaya C., Uzan S. Desalination and Water Treatment, 2012, Vol. 44, pp. 296-305.

20. Coruh S., Geyikci F. Desalination and Water Treatment, 2012, Vol. 45, pp. 351-360.

Linnikov Oleg D. - Head of Laboratory, PhD, Dr. Sci. (Physical Chemistry), Institute of Solid State Chemistry, Ural Branch of the Russian Academy of Sciences, Ekaterinburg, E-mail: linnikov@mail.ru

Rodina Irina V.- researcher, Institute of Solid State Chemistry, Ural Branch of the Russian Academy of Sciences, Ekaterinburg

Suntsov Alexey Yu. - Senior Researcher, PhD, Institute of Solid State Chemistry, Ural Branch of the Russian Academy of Sciences, Ekaterinburg 